\title{
VIVIENDA Y PAISAJES RURALES EN SIERRA MORENA
}

\author{
Ricardo Manuel Luque Revuelto \\ Departamento de Ciencias del Territorio \\ Universidad de Córdoba
}

\section{RESUMEN}

La vivienda rural cobra hoy en día mayor importancia y un nuevo significado desde el punto de vista de la consideración del patrimonio y del paisaje. El objetivo del presente artículo es poner de manifiesto la singularidad de la vivienda rural en los espacios mariánicos como uno de los elementos más característicos y definidores de unos paisajes agrarios que se vinculan tradicionalmente a la montaña baja y media mediterránea.

Palabras clave: Paisaje, geografía rural, hábitat rural, Sierra Morena.

\section{ABSTRACT}

The rural housing now becomes of great importance and a new meaning from the point of view of the consideration of heritage and landscape. The aim of the present article is to highlight the uniqueness of rural housing in the spaces mariánicos as one of the most characteristic and defining of agricultural landscapes that are traditionally linked to the lower and middle mountain mediterranean.

Key words: landscape, rural geography, rural habitat, Sierra Morena.

\section{Introducción}

En el presente trabajo se quiere rendir homenaje in memoriam al profesor Antonio López Ontiveros con el que muchos de sus alumnos y ahora profesores mantuvimos una entrañable relación humana y científica. D. Antonio terminó por encauzar nuestra actividad intelectual por los derroteros de la Geografía de manera que muchos aprendimos a entender y a valorar, según sus palabras, esa realidad ecológica y muy especialmente cultural que es el paisaje.

Su particular visión del paisaje, científica y profundamente humanística, y la vitalidad demostrada en el estudio y defensa de los elementos naturales y humanos que conforman los paisajes andaluces nos ha llevado a tratar de profundizar, en uno de

1 En homenaje al Profesor D. Antonio López Ontiveros. 
los espacios más queridos por D. Antonio: la penillanura mariánica, en sus espacios rurales $\mathrm{y}$, de manera mucho más concreta, en una pieza clave que conforma dichos espacios: el hábitat rural.

La vivienda rural cobra hoy en día una gran importancia y un nuevo significado desde el punto de vista de la consideración de los paisajes rurales, importancia que no está reñida con una extraordinaria complejidad del tema o incluso con una problemática no resuelta en lo que se refiere a su singularidad, conocimiento, valoración y defensa.

Los objetivos del presente artículo son varios: se trataría, en primer lugar, de revisar el concepto de vivienda rural, analizada ahora desde el punto de vista del paisaje para tratar, a continuación, de poner de manifiesto la singularidad de la misma, atendiendo tanto a los factores tanto físicos como humanos que la conforman. Seguidamente se procura distinguir los caracteres comunes de las viviendas rurales y poner de manifiesto su particular relevancia. Finalmente, en un apartado relativo a la gestión y protección de dicho hábitat, se aborda su defensa desde un punto de vista patrimonial - más consolidado - y, a continuación desde las nuevas e incipientes directrices que se vienen proponiendo desde el punto de vista del paisaje.

Pensamos así que la noción de paisaje, pese al carácter complejo del término, pueda llevarnos a la mejor comprensión de uno de los elementos más característicos y definidores de los paisajes agrarios mariánicos como es el hábitat rural y, de esta manera, contribuir a un mejor entendimiento de la totalidad geográfica o territorial de unos espacios que se han vinculado paisajísticamente con la montaña baja y media mediterránea.

\section{Vivienda rural y concepto de paisaje}

Desde hace algunos años venimos asistiendo a un renovado interés por todo lo que se relaciona con el paisaje. Los colectivos culturales, sociales y académicos interesados por el paisaje se han ampliado y diversificado, lo que se ha traducido en un enriquecimiento del término. Una nueva consideración identitaria, una lectura renovada y un dilatado cariz histórico y cultural empapa ahora el concepto de paisaje que adquiere una marcada dimensión poliédrica, no restringida a un campo particular, sino como eje que viene a articular toda la realidad geográfica.

Ya lo expresaba el profesor Eduardo Pisón hace tres décadas, llegando a definirlo como: «la configuración de la realidad geográfica completa, o, si se prefiere, la morfología de los hechos geográficos» (Martínez, 1977: 157-161); y más recientemente, la Convención Europea del Paisaje lo designaba, en 1997, como: «cualquier parte del territorio, tal como es percibida por las poblaciones, cuyo carácter resulta de la acción de factores naturales y/o humanos y de sus interrelaciones» (art. 1). Definición esta que procura conciliar los aspectos naturales y culturales, identitarios o subjetivos con los objetivos, y - lo que resulta una auténtica novedad - , la extensión del concepto de paisaje a la totalidad del territorio, sean espacios naturales protegidos, rurales, urbanos o periurbanos, incluso las aguas interiores o marítimas (arts. 2 y 15).

De forma intencionada la CEP, en su definición de paisaje, procura no adjetivar el término en un intento de extender el concepto a la totalidad del territorio. En nuestro caso aludimos a un determinado tipo de paisajes: los paisajes rurales. Así el término sirve para designar los rasgos dominantes o los tipos de procesos que explican de forma preferente la dinámica de estos espacios pero sin perder por ello la amplia y vigorosa semántica del término paisaje. Es más, con las renovadas connotaciones que implica el término paisaje los espacios rurales y los elementos que los componen adquieren una nueva dimensión que viene a completar las conocidas aproximaciones a los espacios rurales de las monogra- 
fías comarcales de gran raigambre agraria de los años setenta y ochenta del pasado siglo (López, 1973; Cruz, 1980; Mata, 1987, entre muchas otras). Obras que incluyen magníficas descripciones de sus respectivos paisajes y análisis meticulosos de cada unos de sus componentes pero que no responden a la más reciente acepción del concepto de paisaje. Un paso adelante supuso la incorporación de matices subjetivos, formales o identitarios enraizados en sus manifestaciones culturales e históricas que aportaron la literatura viajera y otras recreaciones y que vienen a consolidar una imagen figurada o alegórica del paisaje (López et al., 1988).

En fechas más recientes los paisajes rurales reciben un nuevo enfoque, el de la ordenación del territorio (Mata, 2004; Zoido, 2000, 2002, 2004) lo que nos lleva a un nuevo planteamiento: el de la ordenación, gestión y protección de estos paisajes. Una triple actitud que supone una visión dinámica del mismo, relacionada necesariamente con las transformaciones inducidas por los cambios económicos, sociales, tecnológicos y medioambientales que vienen a modificar no solo los paisajes rurales y cada uno de sus componentes, sino el concepto que existía sobre cada uno de ellos y de sus respectivos elementos, desde los sistemas de cultivo hasta la humilde vivienda campesina adquieren a la luz del postproductivismo y de la reciente noción de paisaje una nueva dimensión.

En esta aproximación conceptual que venimos realizando nos resta hacer referencia al concepto de vivienda rural que, de la misma manera que en los anteriores conceptos, va a ir experimentado nuevas matices a la luz de aspectos naturales, culturales, patrimoniales, sociales y subjetivos o identitarios que propone la definición dada por la Convención Europea del Paisaje a «cualquier parte del territorio».

La casa campesina es uno de los elementos más visibles y definitorios de los paisajes agrarios, tanto las que aparecen dispersas en el medio rural - tratándose no solo de un elemento más de los paisaje agrarios mariánicos - , como aquellas otras que conforman los blancos caseríos de los núcleos de población - en donde constituyen la pieza fundamental y a veces exclusiva de los paisajes urbanos inscritos en el medio rural- - También son sobre las que más directamente han incidido los cambios estructurales acaecidos en las actividades agrarias, de manera que han debido someterse a nuevas funciones cuando no al abandono y la ruina.

Hasta hace poco tiempo no se ha roto con una imagen tópica de una arquitectura serrana que se tipificaba bajo los estándares de una pretendida y uniformizadora «arquitectura andaluza típica» de casa blanqueadas con patios y rejas rebosantes de colores vegetales. Aspecto este que viene, en este y otros semblantes geográficos, a completar el tópico de Andalucía. Tópico que, en este aspecto de nuestra geografía regional, se han encargado de desmontar Carlos Flores (1973), Feduchi (1978), Garcia Mercadal (1981) o Caro Baroja (1990), los cuales han despojado la arquitectura andaluza de los apelativos estándares que la generalizaban y han sido capaces de caracterizar las múltiples particularidades constructivas de las viviendas de las comarcas andaluzas.

La arquitectura tradicional debe ser interpretada, antes que nada, como testimonio privilegiado que nos habla de la riqueza y diversidad de los paisajes rurales mariánicos, sin olvidar que la casa rural tiene un profundo sentido geográfico o como afirmaba Sorre (1952) que: «es la depositaria de del testimonio más completo de la unión del grupo humano y la tierra que cultiva», a lo que añade Demangeon (1963): «la casa es el elemento más vivo de los que componen el paisaje rural» ${ }^{2}$, por lo que, la vivienda rural está ligada estrechamente a las condiciones del medio natural y es un hecho funcional, reflejo de la vida misma del campesino que resuelve las necesidades materiales de su vida cotidiana de

2 El autor llega a comparar la casa con un ser vivo, una criatura modelada por siglos de vida rural. 
la misma manera que sucede en otras funciones o actividades humanas como puedan ser las estudiadas por la geografía de la población o la geografía económica.

Deffontaines (1972) va más allá al afirmar que la casa rural, no solo es la prueba más geográfica del trabajo del hombre - más incluso que los campos de cultivo-, sino que es el hecho que sintetiza la vida misma de estos hombres, su esfuerzo, su pensamiento y su grado de evolución. Razón por la cual otros estudiosos, de diferentes disciplinas, son atraídos hacia su conocimiento al igual que el geógrafo.

Gorou (1979) da un paso más al elevar el hábitat rural a un plano superior dentro de las ciencias sociales, asignándole un papel fundamental en la civilización, papel que le confiere una dimensión histórica y cultural omnipresente en la configuración de los distintos paisajes humanos que han poblado la Tierra desde el comienzo de la Humanidad.

Así, tempranamente, los geógrafos franceses ya habían aportado al término de hábitat rural las connotaciones que se le asignan recientemente al paisaje: su dependencia del medio físico, el componente cultural, la dimensión histórica y patrimonial, el valor identitario, etc. Connotaciones estas que descubrimos en los estudios regionales andaluces o comarcales sobre hábitat rural y que jalonan la segunda mitad del siglo XX (Valle, 1978; Suárez, 1982; Agudo, 1984; Ramírez, 1985; Bergues, 1986; Aguilar, 1992; Florido, 1996; Dirección General de Arquitectura y Vivienda, 1998, citando solo algunos de ellos)

Solo resta para completar la visión más amplia del hábitat rural la de agregar la consideración relativa a la adopción de medidas de protección, ordenación y gestión superando las opciones excepcionalistas o meramente proteccionistas que se incorporarían a finales del siglo XX y comienzos del presente. Como consecuencia de todo ello, y por vez primera en la historia del hábitat rural y de los paisajes de la agricultura, estos han comenzado a adquirir categoría sustantiva a efectos jurídicos y empiezan a definirse dentro de un marco legal conducente a su consideración como patrimonio - aspecto este que trataremos en el último epígrafe del presente artículo-.

En definitiva, estamos ante tres conceptos - paisaje, paisaje rural y casa rural - estrechamente relacionados, pero que han caminado no siempre de la mano, conceptos de gran raigambre en el conocimiento de los hechos geográficos, nociones que se han acrisolado tras una dilatada y fecunda evolución científica permitiendo entender de forma sintética la realidad que nos envuelve. Así la vivienda campesina, desde el punto de vista del paisaje, multiplica su interés porque advertimos en ella una realidad espacial, sintética y dinámica, que se manifiesta en forma de paisajes rurales singulares que representan, a su vez, una apretada suma del entorno físico, humano, cultural e histórico que le rodea. Esa pervivencia del hábitat en los paisajes rurales hace que sea el elemento que más tarda en cambiar y es debido, por una parte a una serie de costumbres arraigadas, pero también porque representa un capital elevado el cual costaría mucho reemplazar - la capacidad económica de muchas familias no lo ha permitido de hecho-. Al igual que cualquier otro hecho sociológico, refleja también una serie de disposiciones mentales que no se pueden reemplazar fácilmente, tratándose, por tanto, no solo de una construcción racional (Derruau, 1981). Aunque estos dos factores se hayan conjugado para que las viviendas rurales muestren una inercia poco favorable a los cambios y transformaciones que presentan otros hechos geográficos, lo cierto es que en el presente, el hábitat rural a reaccionado en los espacios mariánicos, de igual forma que en toda Andalucía, ante las innovaciones derivadas del uso de nuevas técnicas y materiales y ante los cambios en los modos de vida. Esas modificaciones han acarreado la estandarización de las tipologías y de los materiales, de manera que cada paisaje ha ido perdiendo aquellos componentes que caracterizaban sus propias formas de hábitat. 


\section{La singularidad de la vivienda rural en los espacios mariánicos}

En Andalucía el paisaje rural cobra una nueva dimensión en los ambientes de media y baja montaña mediterránea localizados en Sierra Morena. Presidida secularmente por una economía agro-silvo-pastoril de autoabastecimiento, la vivienda rural se adaptaba de forma proverbial a los hostiles condicionantes del medio, mediante un aprovechamiento máximo de los recursos edáficos y climáticos, y presidia, de esa manera, una serie de paisajes agrarios diversos que formaban un mosaico en derredor de los pueblos: pequeñas huertas, ruedos con hazas de cereal de secano, parcelas de viñedo u olivar y extensos espacios adehesados $\mathrm{y}$ forestales. Marginados por el agricolismo ilustrado, los paisajes rurales entroncaron un siglo más tarde con el ideal de belleza paisajística de los viajeros románticos, de manera que estos paisajes trascenderán desde finales del siglo XIX hasta llegar a finales del siglo XX a contemplar la aparición de nuevos planteamientos neorurales o ecológicos que pretenden reconstruir algunos de sus tradicionales paisajes.

Sea como fuera, en el curso de esta evolución, la arquitectura rural tradicional de los espacios mariánicos ha carecido de un conveniente y necesario estudio de conjunto que analice con profundidad todos y cada uno de los aspectos relacionados con ella y con los paisajes en los que se inserta. Pocos han sido los trabajos que se han acercado a esta arquitectura doméstica y, por lo general, de forma tangencial y por medio de referencias aparecidas en publicaciones de muy diversa índole.

\subsection{Factores físicos que conforman la vivienda rural}

Muchos de los rasgos básicos de las construcciones rurales mariánicas se derivan de la estrecha relación que la casa rural establece sobre el medio físico sobre el que se asienta. Dicha relación se fundamenta en una adaptación del hombre a las condiciones naturales del entorno, la consideración de las cuales resulta ser un paso previo imprescindible a la elección del emplazamiento y a la misma construcción de la vivienda. Por tanto, la casa establece un fuerte vínculo con el territorio, vínculo que actualmente aparece roto por lo avances técnicos, los modelos estandarizados y los materiales prefabricados.

El relieve juega un papel importante en el emplazamiento de caserías y cortijos de la misma manera que en los núcleos de población. Dadas las peculiaridades de la topografía mariánica se suelen ocupar puntos elevados sobre pequeñas y redondeadas lomas que permitan un cómodo acceso por una suave pendiente. En este caso la necesidad defensiva no es la causa de los emplazamientos pues se corresponden con una ocupación intercalar secundaria de época reciente en la que no era preciso considerar este factor. Pero si pueden responder a un deseo de conseguir una mejor vigilancia de los campos de forma que puedan otearse desde esas zonas encumbradas; además de contar con un microclima más favorable que permite beneficiarse de las brisas más frescas de la tarde; o de contar, por ejemplo, con una era cercana en donde aventar la parva. La facilidad de construcción en pendiente, la huida de terrenos mal drenados o encharcados, o la proximidad de la roca madre que minimice la cimentación, pueden ser otros factores que coadyuven a la elección de dichos emplazamientos, si bien este emplazamiento conlleva un mayor desarrollo de la vivienda en altura. Los edificios que se localizan en el área granítica de los Pedroches, en una topografía plana, por el contrario, presentan un mayor desarrollo en superficie, adoptando consecuente una tipología o plano diferente a los anteriores.

Los materiales empleados (la piedra, la tierra, la madera) para levantar las construcciones rurales se obtienen del entorno inmediato. Su empleo, que responde a una cuestión de eficacia y economía, manifiesta una perfecta imbricación con el medio natural sobre el que 
se asientan las casas y contribuye a integrar perfectamente las construcciones en el paisaje circundante. Asimismo, el empleo de diferentes materiales, dependiendo de las características litológicas o edafológicas de cada zona, nos permite establecer heterogéneas técnicas constructivas tradicionales y, por supuesto, diferencias intercomarcales de cierta entidad.

La disponibilidad de agua para el uso domestico y las necesidades del ganado han sido un factor de peso a la hora de decidir el emplazamiento de esta, máxime si tenemos en cuenta que en los espacios mariánicos la existencia de manantiales naturales o de ríos que mantengan un mínimo caudal durante todo el año son muy infrecuentes por la naturaleza del roquedo de Sierra Morena y por el carácter estacional de las precipitaciones. La alternativa para obtener dicho suministro era perentoria y desde luego considerada previamente a la elección del emplazamiento. La solución adoptada en la mayoría de los casos consistía en la construcción de pozos artesianos y de aljibes para almacenar el agua, por lo que era imprescindible la pericia de un zahorí que localizase los mantos freáticos con mayor manantial y más próximos a la superficie, los cuales se localizan próximos a los arroyos y afluentes mariánicos. El análisis de la cartografía nos permite hacernos una idea de la intención del agricultor por situar su vivienda próxima a un punto de abastecimiento de agua, si bien a una distancia prudencial para evitar el riesgo de avenidas, o en una loma cercana cuando el curso fluvial se encaja formando barrancos. La disponibilidad de agua resulta particularmente necesaria en los cortijos de olivar tradicional que contaban con almazara, ya que era necesaria gran cantidad de ella para la molturación de la aceituna. Aunque no es menos importante en las explotaciones de dehesa o de tierra calma, habida cuenta de las necesidades del ganado, tanto del de carne como del de labor.

El clima es sin duda un factor de gran importancia, aunque menos que el anterior. Las técnicas constructivas y los materiales empleados no pierden de vista las elevadas temperaturas del verano y los inviernos, más rigurosos que en las campiñas béticas. Así el grosor de los muros, las cubiertas vegetales y elementos como los soportales, terrizos o emparrados se adecuan o destinan, según su caso, al fin de aclimatar las viviendas. Respecto a la orientación dominante puede decirse que las fachadas se abren a todos los vientos, puesto no se cumple la pauta observada religiosamente en otras regiones, en donde las casas miran al sur o al este para protegerse del frio invernal y de las lluvias. Las caserías montoreñas y los cortijos y casas de labor, situadas en el piedemonte de Sierra Morena, suelen mirar al Guadalquivir desde su privilegiada posición, adoptando una orientación sur. En muchos casos, a falta de otro criterio, la casa mira hacia donde se encuentra el acceso de la finca, el camino o carretera por la que se llega a la edificación determina la orientación del acceso principal y por tanto del plano que le sobreviene.

\subsection{Factores humanos que conforman la vivienda rural}

Entre los factores humanos uno de más determinantes es la poca entidad que presenta el poblamiento mariánico, tanto el concentrado como el disperso. El Plan de Ordenación del Territorio de Andalucía (1999). Diagnosticaba Sierra Morena como el de un espacio fuertemente desestructurado como consecuencia de la baja densidad de población, la ausencia de ciudades medias con la excepción de Pozoblanco y la debilidad de la trama de poblamiento rural, con escasos Centros Rurales que posean capacidad de organizar amplias zonas rurales, las cuales quedan desarticuladas. También se detectan las escasas y deficientes conexiones que priman la salida de los Centros Regionales hacia el exterior y los flujos de turismo y segunda residencia de ellos provenientes, más que su articulación interna. Otra característica es la constatación de aparición reciente de nuevos procesos urbanísticos e instalaciones turísticas que alteran la trama de asentamientos históricos y generan impactos 
paisajísticos y ambientales. Complementariamente a las funciones de turismo rural, que se asientan en la extensa red de espacios protegidos, se aprecia un desarrollo autónomo que tiene que ver con la puesta en valor de recursos propios y de manera muy particular con el sistema agrario de la dehesa, elemento identificador de buena parte del paisaje mariánico.

En la franja norte de la provincia de Córdoba encontramos la trama más densa y potente de asentamientos humanos de toda Sierra Morena, por el contrario esta realidad se manifiesta en áreas funcionales independientes y escasamente integradas entre sí y con las dinámicas urbanas del Valle del Guadalquivir. En las planicies superiores del Guadiato y en los Pedroches existía una red de ciudades medias considerable que ahora ha quedado reducida a Pozoblanco y Peñarroya-Pueblonuevo, y los centros rurales de menor importancia han perdido capacidad de organización del mundo rural, resultando amplias zonas rurales de Sierra Morena desarticuladas y con una clara dependencia funcional de otros centros comarcales ajenos o externos a los espacios mariánicos, caso de la Sierra de Aracena onubense, la Sierra Norte de Sevilla, las comarcas del norte de la provincia de Córdoba o la zona septentrional de Andújar y Linares en Jaén. Así muchas comarcas han quedado en una situación excéntrica respecto de los ejes más dinámicos del conjunto andaluz: a saber, el Litoral y el Valle del Guadalquivir. La pérdida de importancia relativa de estos espacios es común al resto de otras áreas de montañas andaluzas y tiene su base el fuerte descenso demográfico sufrido desde mediados del siglo XX y que aquí se vio agravada por la crisis de los distritos mineros.

Desde los años ochenta, sin embargo, asistimos a la consagración de tendencias anteriores y a la aparición de nuevos procesos. Así los ámbitos mariánicos se consolidan como proveedores de recursos agrarios, forestales y naturales (como por ejemplo recursos hídricos) para otras áreas con dinámicas urbanas y agrícolas más intensas situadas en el Valle del Guadalquivir. Por otro lado, estos espacios, pasan a ser receptores de la población de esas áreas más dinámicas que buscan oportunidades de recreo y ocio bajo los estándares de nuevas actividades relacionadas con el turismo, natural, rural y cinegético (López et $a l ., 1989)$. En ellos han tenido mucho que ver la nueva puesta en valor de sistema agrario de dehesa y de los recursos naturales mediante la declaración de Parques Naturales y otras figuras de protección medioambiental en grandes extensiones mariánicas. Ello junto a las experiencias de aplicación de programas de desarrollo rural ha permitido el impulso de procesos endógenos de crecimiento económico a partir de actividades productivas locales.

Peor suerte ha corrido el diseminado mariánico, puesto que su capacidad demográfica es reducidísima respecto al hábitat concentrado. A excepción de las primeras décadas del siglo XX y de la ligera inflexión positiva de los años 50, los habitantes que residen en diseminado no han hecho sino disminuir hasta representar menos de un 5 por ciento de los efectivos demográficos actuales (Florido, 2003: 331). Es por ello que las casas rurales ya deshabitadas se caen ante la pérdida de su función principal: la de residencia del campesino y de su familia, que aprovechando los medios de transporte actuales ya reside en el núcleo principal de su municipio. Por tanto, el mal estado de conservación y el deterioro constante de las edificaciones viene a ser otro de los factores característicos que hacen temer por la desaparición esta arquitectura vernácula. Asimismo hoy en día no se pueden entender los paisajes agrarios de Sierra Morena sin tener en cuenta esta realidad, los espacios rurales están desiertos, buena parte de la arquitectura y de los caminos o vías pecuarias han desaparecido; en definitiva el campo se ha despoblado en esta agricultura sin agricultores, cuando hasta hace tan solo unas décadas, según afirman los testimonios orales, las ventas y los caminos de Sierra Morena se encontraban rebosantes de arrieros, comerciantes, jornaleros, tratantes de ganado, pastores, labradores y jóvenes que mantenían vivos unos espacios y unas tradiciones que ya son parte del pasado. 
En lo que respecta al grado de desarrollo de las edificaciones podemos afirmar que está en estrecha consonancia con el tamaño de las explotaciones agrícolas. El grado de desarrollo de la casa rural y de su número y tamaño de dependencias es testigo visible del tamaño de las fincas sobre las que se asienta aunque no apreciemos los límites de la propiedad. Este factor es el que explica que sobre una misma topografía o unos idénticos aprovechamientos se pase de una pequeña casa-bloque de una planta a otra con patio y múltiples dependencias en las fincas de mayor tamaño.

El aprovechamiento agrario determina el tipo y el número de dependencias que aparecen junto a la vivienda campesina, pudiéndose dar varios casos:

- El cultivo del olivar puede simplificar mucho el plano de la casa cuando se trata de pequeños propietarios y, por tanto, no existe molina. La topografía accidentada favorece la construcción de una casa bloque en altura. La parte inferior actúa como vivienda permanente del agricultor y la superior como lugar de alojamiento de la faneguería durante el tiempo de recolección de la aceituna. Las dependencias secundarias son mínimas y se reducen a una pequeña cuadra para la yunta de mulos que laborean el olivar y acarrean la aceituna a la molina más próxima. Para el autoconsumo se levanta un corral para gallinas o cerdos separados del edificio principal. Nada que ver tiene esta casa con las caserías de olivar de los grandes propietarios de Adamuz y Montoro o con las haciendas sevillanas.

- El aprovechamiento cerealístico requiere un mayor desarrollo de la casa en superficie. Esto se traduce en el mayor tamaño y número de las dependencias, que pueden dar lugar a la aparición de la casa con patio, abierto o cerrado, lo que la identifica con el denominado cortijo andaluz. Cuando se trata de una gran propiedad se disocian los elementos: la vivienda de los propietarios, las de los capataces y obreros, de las instalaciones de la explotación cerealística y de los espacios asignados al ganado. No es infrecuente que tal separación pueda ser incluso superior a $1 \mathrm{~km}$ cuando las fincas tienen un tamaño considerable o tienen una parte de sierra o adehesada.

- El aprovechamiento ganadero se asocia necesariamente a las explotaciones de olivar como comentábamos y también a las de cereal, hecho razonado por el sistema de barbecho y por la necesidad de la fuerza de tracción animal para el laboreo y el transporte. Cuando los aprovechamientos son exclusivamente ganaderos supone una reducción de las dependencias que se limitan a un corral o cuadras para el ganado además de la residencia de los ganaderos, pudiendo ambas mantenerse unidas o alejadas entre sí. Cuando el tipo de aprovechamiento ganadero lo requiere y el ganadero debe desplazarse con sus animales el hábitat se adapta a estos condicionantes pasando a segundo plano, es así como aparece una vivienda mínima, muy abundante y hoy ya desaparecida, que fueron los chozos y las casillas.

La propiedad es un elemento de los paisajes agrarios que determina, el tamaño, la distribución y los materiales de la vivienda rural, de la misma manera que lo hacía en la vivienda urbana. Pero en el medio rural, a diferencia del urbano, la estructura de la propiedad ha sufrido grandes alteraciones a lo largo del tiempo, y particularmente, desde el siglo XIX, de manera que se han producido importantes transferencias de propiedades nobiliarias y eclesiásticas, ventas de terrenos comunales y bienes de propios; cambios que han conducido a una fragmentación o a una concentración de la propiedad en pocas manos. El hábitat no ha sido ajeno a estos cambios, haciendo acto de presencia en las propiedades recién adquiridas tras las desamortizaciones como manifestación de la voluntad de sus nuevos propietarios por poner en explotación esas tierras y evidenciar la nueva titularidad de las mismas. Nuevas viviendas, pozos, norias, molinas, vallados o cercados de piedra serán los 
componentes que salpican el paisaje mariánico a medida que avancen las transferencias de la propiedad en el siglo XIX ${ }^{3}$.

De la misma manera el abandono de explotaciones y la venta de las menos rentables, a partir de la crisis de la agricultura tradicional a mediados del siglo XX, propició la perdida de ese hábitat o su readaptación a nuevas funciones. Las viviendas que todavía permanecen en pie no han sido ajenas a todos esos cambios, de manera que muestran una yuxtaposición formal y estética, adoptando múltiples e irregulares formas. Su tamaño se ha contraído o dilatado según los requerimientos de la propiedad, de manera que es frecuente encontrar distintas dependencias que se corresponden con épocas diferentes.

El resultado de todos estos factores, tanto físicos como humanos, ha sido la gran diversificación en las formas, tamaños, planos y número de dependencias de las edificaciones, y aún, pudiéndose establecer algunas clasificaciones, difícilmente estas pueden abarcar la extraordinaria casuística que comprende el paisaje rural edificado.

\section{Caracteres comunes a la vivienda rural mariánica}

Representar mínimamente cada uno de los tipos de vivienda rural que ha construido la trayectoria histórica y la variada y rica cultura mariánica excedería los límites del presente artículo. Pero de forma simplificada podemos establecer dos grandes categorías: por un lado la vivienda agrupada en los núcleos de población o hábitat concentrado y por otro lado la vivienda diseminada o hábitat disperso.

Los pueblos, villas y aldeas de Sierra Morena constituyen un rosario de ciudades medias que desde Huelva a Jaén siguen funcionando como centros neurálgicos en la organización territorial de estos espacios. No se trata de grandes agrovillas como las existentes en la campiñas béticas, sino más bien de centros intermedios que actuaron y lo siguen haciendo como cabeceras comarcales: Cortegana, Aracena, Constantina, Cazalla, Peñarroya, Pozoblanco, Villanueva de Córdoba, La Carolina, etc.; y de un conjunto extenso de pequeños pueblos y aldeas dependientes de aquellos.

Los conjuntos urbanos se han ido enriqueciendo con un relevante patrimonio histórico tanto civil - ayuntamientos, pósitos, fortalezas - como religioso - ermitas, iglesias, mezquitas - que en muchos casos han sido declarados monumentos de interés cultural. Pero también cuentan con extensos caseríos bien conservados que por encontrarse alejados de las dinámicas urbanas, más intensas en el valle del Guadalquivir y en el litoral, han conservado buena parte de las construcciones asociadas a las actividades agrarias predominantes, como los molinos, lagares, bodegas y diversas industrias relacionadas con la artesanía o la minería, así como estructuras y redes relacionadas con dichas actividades, como puedan ser las fuentes, abrevaderos, empedrados, etc.

El predominio casi absoluto del poblamiento concentrado no impide la existencia de abundantes edificaciones rurales dispersas que presentan una tipología diversa que se relaciona con su funcionalidad y el tipo de explotaciones en las que se integran. El repertorio de formas de hábitat es extenso y desde luego mucho más amplio de lo que parece indicar el uso de de un termino de gran tradición en el lenguaje popular como es el de cortijo. En ese sentido denominaciones como haciendas, casas, caseríos, casillas, casas de dehesa, caserías, casas de labor, casas de huerta, haciendas, lagares, chozos, chozas, etc., no son sino formas particulares de habitación con una forma propia y una funcionalidad específica.

3 En la toponimia se puede constatar de forma visible este hecho, así aparecen de forma muy profusa el nombre de los propietarios de las nuevas edificaciones o explotaciones. Por ejemplo: «Cortijo de las Torricas», «Casa de José Salamanca», «Lagar de Francisco Barahona», «Molino de Manuel Garijo», etc. Expresiones estas que no hacen sino confirmar sobre el terreno, la nueva titularidad de dichas propiedades. 
La orientación productiva de las explotaciones viene a ser el principal factor de clasificación de estas edificaciones, aunque no es el único: la disposición del plano o los materiales utilizados son otros criterios de clasificación empleados tradicionalmente por diversos autores, sobre todo por los de la escuela francesa ${ }^{4}$. Sierra Morena está constituida por unos espacios de tradicional vocación ganadera y de cultivos relacionados con la trilogía mediterránea en un contexto de agricultura atrasada y de subsistencia, es por ello que la necesidad de una complementariedad en los aprovechamientos, la necesidad de alternar las tareas agrícolas y la falta de uniformidad que introduce el relieve o los tipos de suelos, haga que no siempre la dedicación agropecuaria de cada explotación sea única. En el monocultivo de olivar es más evidente que en los aprovechamientos cerealísticos y ganaderos, apareciendo estos combinados frecuentemente. Pero debemos insistir en que, por ejemplo, la separación cortijo-cereal o caserío-olivar no es tan nítida como en tierras campiñesas o en la depresión del Guadalquivir, espacios estos caracterizados por una mayor fertilidad, diferente estructura de la propiedad y una mayor especialización productiva.

La toponimia por su valor identificativo y locacional es un elemento imprescindible en la representación cartográfica de un territorio. Es por ello que contiene información referente a las edificaciones rurales, particularmente a la tipología del hábitat, a los cultivos o a los tipos de explotación que distinguen. En efecto, en la toponimia de Sierra Morena (Consejería de Obras Públicas, 1990) se localizan edificios relacionados con la explotación ganadera: ahijaderos, borregueras, caballerizas, cabrerizas, cebaderos, corrales, corralizas, corralones, cuadras, criaderos, dehesas, establos, majadas, pesebreras, ranchos, ranchillos, vaquerizas y zahúrdas; otros que combinan la residencia del campesino con las explotaciones cerealísticas son: cortijos, cortijillos, eras y molinos; con la explotación del olivar: haciendas, casas, caserías y molinas; con el viñedo: viñas, lagares y lagarillos; con la huerta: huertas y granjas; con otras actividades rurales: almacenes, barracones, batanes, caleras, posadas, ventorrillos y secaderos; tampoco están ausentes las viviendas mínimas en la toponimia: casetas, casillas, chozas y chozos; por último, algunos están mal definidos o relacionados con explotaciones mixtas: fincas, casas, viviendas, etc.

La forma más adecuada de presentar cada una de las tipologías de hábitat, teniendo en cuenta las consideraciones expuestas, resultaría ser aquella que se inicie con una descripción que explique su localización geográfica y distribución en el espacio serrano, de forma que quede patente su inserción en el paisaje y la interconexión que preside las mismas y su entorno inmediato. A continuación es obligado recabar la estructura de los edificios y su organización funcional atendiendo a las piezas que los componen y su disposición espacial sobre el plano. Tras esta cuestión se abordarían las características constructivas y aspectos morfológicos que vienen a caracterizar su fisonomía y, a su vez, ayudan a diferenciar algunas variantes comarcales propias.

Las posibles tipologías expresadas, claramente observables en los paisajes rurales mariánicos, no son sino un síntoma más de su riqueza y diversidad cultural. Peo aún así nos muestran una serie de caracteres comunes a todas ellas, caracteres que las dotan de

4 Así Tricart emplea como criterio de clasificación la diferenciación de los planos: casa bloque, a ras de suelo o en altura, y la casa disociada, con patio abierto o cerrado. Véase: TRICART, J., L'habitat rurale. Cours de Géographíe Humaine. Paris, Centre de Documentación Universitaire. (1. a ed. sin fecha), 36 y ss. Por su parte Demangeón diferencia, en principio: la casa elemental, en bloque, disociada y en pisos. Pero más tarde considera que van a ser las dimensiones de las explotaciones la pieza clave que permite diferenciar los tipos de viviendas rurales. Véase: DEMANGEON, A. (1963): Problemas de Geografía Humana. Barcelona, Ed. Omega, p. 163 y ss. Derruau presenta en su estudio multitud de ejemplos tomando como criterio calificatorio la distinción entre casa bloque y casa disociada, pero insiste en la importancia de los materiales, en los hechos históricos y, sobre todo, en la función agraria para la cual se adoptan esos planos. Véase: DERRUAU, M. (1974): «Los problemas del hábitat rural», en Tratado de Geografía Humana. Barcelona, Vicens-Vives, pp. 413 y ss. 
unicidad dentro de los paisajes serranos de montaña baja y media mediterránea andaluza que es Sierra Morena. Son estas:

- En todas las edificaciones, aunque las formas sean diferentes, predomina un sentido unitario y simbiótico con el medio donde se insertan, sentido que adquieren por la utilización de unos materiales y unas técnicas constructivas tradicionales. Las casas diseminadas que sobresalen por su volumen o por su blancura en los espacios de dehesa, de olivar o de tierra calma forman parte consubstancial del paisaje agrario de Sierra Morena de forma que su presencia nos parece natural, como si fuesen continuación de los cultivos, de los árboles o del relieve.

- Además, la vivienda rural en los paisajes mariánicos, no solo está perfectamente imbricada con el medio sino que además dota a este de una unidad y una particularidad que lo hace perceptible, no solo para los que se acercan a su estudio, sino a todos los que lo contemplan. La uniformidad en los modos constructivos, la escasa variedad de tipos, la dualidad de aprovechamientos y de usos, agrícola y ganadero, sus dimensiones contenidas y el omnipresente encalado de sus muros nos señalan una realidad geográfica que se fundamenta en el acervo común del campesino por compartir y explotar un medio frágil, pobre y ante un clima hostil, con los cuales tiene el hombre que establecer un equilibrio que permita de forma sostenible los necesarios aprovechamientos agrícolas y ganaderos para su sustento.

- Dicha unidad no está reñida con la existencia de cierta heterogeneidad de formas o tipologías puesto que la vivienda rural es producto de la iniciativa del agricultor, de sus posibilidades económicas, de las características de su explotación y de los condicionamientos del medio físico. Estas particularidades propias de los espacios mariánicos han contribuido a que este hábitat intercalar establezca nítidas diferencias con el del resto de la provincia y de amplias regiones de Andalucía, presentando, por el contrario, cierta analogía con el de la penillanura extremeña.

- Otra particularidad de las viviendas rurales dispersas mariánicas es que en la mayor parte de los casos se trata de unidades que son funcionalmente mixtas y resuelven tanto las necesidades de una ganadería rudimentaria como de una agricultura poco evolucionada.

- La escasa entidad edificatoria, la práctica ausencia de elementos decorativos o la inexistencia del señorío son características comunes que nos muestran la modestia o austeridad constructiva de la vivienda rural mariánica. Hecho que se justifica por la existencia de una pequeña y mediana propiedad que obtiene pobres rendimientos y que por tanto no permite levantar ostentosas construcciones como las del Valle del Guadalquivir. En ellas no percibimos otra cosa que lo estrictamente necesario, un soplo de austeridad, de dificultades sobrellevadas mediante sacrificada permanencia en los terruños, al amparo de unos muros blanqueados que cobijan al agricultor y a su familia. Austeridad esta que no está reñida con una profunda sensibilidad tradicional por la calidad formal y estética de los espacios vividos.

- Tampoco la anterior característica está reñida con apreciable solidez de las construcciones, mayor si cabe que las campiñesas. La razón de ello estriba en el empleo de la piedra (granítica, molinaza, caliza o pizarrosa), abundante en Sierra Morena; la disponibilidad de madera de encina y de otras especies que permiten, en combinación con la teja curva de barro cocido crear cubiertas duraderas; y el empleo de técnicas constructivas acrisoladas en el transcurso de los siglos. Elementos todos ellos que sin duda han dotado de gran solidez y durabilidad a estos edificios que de manera invariable han presidido y aún presiden buena parte de las explotaciones agrarias actuales. 
- Cualquiera que sean las manifestaciones de hábitat rural, por modestas que estas sean, constituyen un hecho geográfico relacionado con el poblamiento que no conviene pasar por alto, pues nos hablan de unos usos y unas formas sostenibles de resolver los asuntos más cotidianos de la existencia entablando una relación con el territorio y sus recursos, incluso en el caso de las viviendas mínimas. Así los chozos, las chozas y las casillas se insertan en ese territorio de forma casi desapercibida, utilizando solo los materiales que la naturaleza ofrece: piedra, madera y vegetales; hasta tal punto que el mimetismo con el paisaje en el que se insertan resulta asombroso. Pero, indudablemente, también nos hablan de unos usos y unos modos sociales asociados a unos periodos históricos concretos en los que los pastores, porqueros, jornaleros $\mathrm{u}$ hortelanos en el último peldaño de la escala social, padeciendo incontables miserias y privaciones, fueron artífices de un hábitat hoy prácticamente desaparecido.

- Como componente cultural que es el hábitat, constituye un elemento vivo y en permanente evolución y transformación, de manera que cuando sus moradores emigraron al extranjero o se marcharon a la ciudad, sucumbieron muchas de estas efímeras construcciones. Pero no solo desaparecieron sus frágiles muros y techumbres, también se derrumbaron los modos y usos sociales de las personas que cobijaban y las técnicas que hicieron posible estas formas de hábitat.

- La casa constituye el corazón y símbolo del conjunto de esta arquitectura, organizada, tanto en asentamientos urbanos, como especialmente rurales. Se concibe como lugar y eje de la vida y actividades tradicionales. Así no es raro que, en la arquitectura tradicional, el concepto y la denominación de casa no sólo se use para identificar el lugar de habitación, sino también al conjunto de la heredad y a los pagos o propiedades a ella vinculada, concibiéndola como un lugar de convivencia y producción como ya afirmaban los geógrafos franceses.

- La casa rural es un conjunto de naturaleza muy diversa, un conjunto diverso y complejo que dota a los paisajes mariánicos y a su territorio de una identidad propia, donde junto a la especificidad local se reflejan las relaciones culturales en las formas arquitectónicas que adquieren, fruto de los distintos intercambios históricos, y en el que cada pieza aparente menor acaba conformando el carácter de estos diferentes Paisajes, que auténticamente se pueden calificar de Culturales.

En este epígrafe se ha hablado de los factores y las características comunes del hábitat tradicional en Sierra Morena sin insistir en las trascendentales consecuencias que sobre la casa rural han tenido la modernización de las estructuras agrarias, el éxodo rural y la generalización de nuevos modos de vida de la sociedad moderna. Sin duda estas modificaciones revisten un indudable interés, pero convendría recapitular e insistir sobre el significado de la arquitectura tradicional y los valores que encierra: es una arquitectura de artesanos no de arquitectos que utiliza modelos cercanos y no modelos eruditos procedentes de libros y tratados; es una arquitectura que emplea recursos o materiales extraídos o producidos localmente; es una arquitectura que sintetiza las transformaciones agrarias acaecidas en el seno de una sociedad rural a lo largo del tiempo; es una arquitectura que evoluciona muy lentamente por razones culturales y económicas, pero no es inmutable ni intemporal; es una arquitectura que se integra perfectamente en los paisajes agrarios en los que se inserta, dotándolos a su vez de significado y riqueza; y es una arquitectura olvidada por los tratados arquitectónicos, por los eruditos y hasta por la escuela.

Puestos de manifiesto los valores de esta arquitectura tradicional, resulta un interés lógico y a la vez contradictorio por conservar, restaurar, rentabilizar, revalorizar o difundir este patrimonio tradicional. Una respuesta o un punto de vista más amplio es el que considera la vivienda rural tradicional como testimonio de la relación del desarrollo de los individuos 
o sus comunidades, y el medio en el que se desenvuelven creando y conformando paisajes naturales y humanos característicos que se han venido en denominar Paisajes Culturales (García, 2007). Territorios de nuestro ámbito geográfico, donde, sin lugar a dudas, la arquitectura tradicional tiene un significativo papel en su materialización y personalización. Por tanto, y sin perder de vista la importancia de los elementos que forman el medio físico de Sierra Morena, hemos de convenir que son los componentes culturales de estos paisajes los que terminan por conformar los paisajes de esta montaña media andaluza. Paisajes que aparentemente están faltos de monumentalidad por su relieve o por los procesos históricos acaecidos en ellos, pero que igualmente se han constituido por un proceso de acumulación histórica que ha ido integrando las aportaciones externas y los modos de civilización de manera que han organizado su espacio de forma particular, conforme a unos valores culturales que han derivado en paisajes característicos, legado del pasado y de la memoria colectiva de sus habitantes (Martínez, 1977). De esta manera La arquitectura tradicional o vernácula debe ser interpretada, antes que nada, como testimonio privilegiado que nos habla de de la riqueza y diversidad de dichos paisajes mariánicos.

Pero no podemos dejar de manifestar una evidente contradicción: considerando los elevados niveles culturales que encierran estos paisajes, podría interpretarse que hayan generado escasos procesos identitarios teniendo en cuenta la escasa alarma que está provocando el cambio, la desfiguración o la desaparición de estos paisajes rurales y de uno de sus elementos más visible como es la vivienda rural, victimas del despoblamiento, la ruina, la especulación o del desconocimiento. Y llama más la atención este hecho cuando consideramos la sensación de alarma que produce en regiones vecinas la desaparición de los paisajes rurales y de sus elementos más emblemáticos por los mismos procesos recientes de cambio. Baste señalar la verdadera crisis cultural que está produciendo este hecho en la sociedad francesa, profundamente identificada con su mundo rural (Galiana, 1996).

\section{Gestión y Protección del hábitat rural en Sierra Morena}

Conscientes de la importancia del hábitat rural no solo desde el punto de vista de la geografía, que es el que aquí nos interesa, sino desde otras perspectivas relacionadas con las ciencias sociales como puedan ser la antropología, el arte, la sociología o la economía, y antes de mostrar cuales son las posibles iniciativas o medidas relacionadas con su valoración, protección o difusión, hemos de considerar sus patologías más comunes, valorando en la medida de lo posible su estado de conservación. Así, en el mejor de los casos todas las viviendas tradicionales, tanto urbanas como rurales, si no han caído en la ruina, sí han sufrido alguna remodelación reciente, pues no olvidemos que están sometidas al continuo desgaste que ocasiona su uso o los propios elementos atmosféricos. Las recomendaciones institucionales y de los expertos han ido en la línea de salvaguardar la arquitectura tradicional, sus materiales y oficios que ayudaron a levantarla. Pero hay que diferenciar los tipos de casa, su uso actual y la posible singularidad de algunas de ellas o de los conjuntos enteros, apostando por soluciones nada fáciles que preserven el patrimonio de la misma manera que el valor de uso de los edificios que, asimismo, tienen que ser habitados por personas de esta época, que demandan unas instalaciones y unos servicios modernos. Muchos coindicen, desde una perspectiva conservacionista, en la necesidad de preservar los ejemplares más señeros o mejor conservados de cada tipo. Pero, para los geógrafos, como ya afirmábamos anteriormente, la destrucción de estos edificios o, por el contrario, la conservación solo de algunos ejemplares significativos nunca podrá compensar la pérdida de un conjunto necesario para poder explicar los paisajes rurales que siguen y seguirán ante nosotros (Zoido, 1979). 
Sería conveniente, antes de continuar analizando las diversas iniciativas y variadas actuaciones que se efectúan en este sentido, establecer una serie de premisas que consideramos imprescindibles en la valoración de la arquitectura rural tradicional mariánica y que bien pudieran tenerse en cuenta a modo de criterios generales para su conocimiento, protección y difusión:

- En primer lugar la arquitectura tradicional debe ser interpretada, antes que nada, como testimonio privilegiado que nos habla de la riqueza y diversidad de la cultura andaluza en general y de las comarcas que analizamos en particular. Se debe por tanto insistir en papel identitario de la misma, pues caracteriza de forma definitoria a una comunidad, al tratarse del testimonio más elocuente de sus formas de vida (Agudo, 1999).

- No se puede olvidar que los hechos del pasado han sucedido en estas calles, plazas, molinos, cortijos, etc. que tratamos, de manera que en aquellos se encuentra la explicación del presente y de los posibles cambios o disfuncionalidades que apreciamos actualmente. La dimensión histórica es imprescindible, por tanto, para el entendimiento de los hechos relacionados con el hábitat.

- Su conocimiento debe procurar el disfrute colectivo de este patrimonio, de manera que sea comprensible y hasta cierto punto visitable para el público en general.

- Ser conscientes de que su conocimiento y difusión es la mejor garantía para salvaguardarlo. Es por ello que la educación cobra un papel primordial en su conservación, pues la ciudadanía sólo defiende aquello que conoce y aprecia.

- Comunicar y aprehender este patrimonio implica unas finalidades que pueden ser culturales, educativas, sociales o económicas lo que requiere situarse a distintos planos: el de la educación formal o reglada, el de la educación informal, o el de los aprovechamientos económicos.

- Las estrategias encaminadas a difundir la arquitectura rural deben estar regladas y ser estables, de manera que la labor iniciada perdure en la ciudadanía y vaya creciendo con ella, es por ello que la escuela sería el mejor vehículo para su difusión. De poco sirven actuaciones puntuales o esporádicas que de vez en cuando nos llaman la tención sobre casos aislados o clamorosos.

- Por otra parte no podemos caer en la alabanza exagerada del patrimonio que disponemos, debiendo procurar un rigor científico y exactitud que sea perfectamente comprensible por la población local y otros colectivos interesados, como puedan ser los visitantes o la población infantil y juvenil.

Así pues la vivienda rural, que comenzó descubriendo un interés geográfico, poco a poco se ha ido haciendo depositaria de un contenido cultural y patrimonial más amplio, y finamente paisajístico.

\subsection{Contenido cultural y patrimonial del hábitat rural}

El contenido cultural y patrimonial del hábitat rural es una apreciación que, podemos decir, comenzó a pergeñarse con los postulados que presentara Demangeon en el Congreso Internacional del Cairo de 1929 y otros de sus colegas en los consecutivos Congresos Internacionales sobre el hábitat rural, y que se han venido sucediendo a lo largo del siglo XX. Pero en esta ocasión vamos a referirnos a las iniciativas más recientes como puedan ser: La carta de Venecia, La Carta del Patrimonio Vernáculo Construido, la Segunda Conferencia de las Naciones Unidas sobre los Asentamientos Humanos o la Declaración de Xi'an.

La Carta de Venecia de 1964 ampliaba la consideración de monumento a las obras arquitectónicas más modestas, que se encuentran diseminadas en el ámbito urbano o rural, 
y que han adquirido con el tiempo un significado cultural de la misma manera que las grandes creaciones.

El Consejo Internacional de Monumentos y Sitios, también conocido como ICOMOS (International Council on Monuments and Sites) es una asociación civil no gubernamental ligada a la Unesco. Fue fundado en el año 1965 en Varsovia tras la elaboración de la Carta Internacional sobre la Conservación y Restauración de los Monumentos y los Sitios Histórico-Artísticos, conocida como «Carta de Venecia» ${ }^{5}$. Su principal objetivo es el de promover la teoría, la metodología y la tecnología aplicada a la conservación, a la protección y a la valorización de monumentos e de sitios de interés cultural. El ICOMOS Es responsable de proponer los bienes que reciben el título de Patrimonio Cultural de la Humanidad.

Posteriormente, en 1999, el ICOMOS redactó La Carta del Patrimonio Vernáculo Construido, como continuación de la de Venecia. En sus declaraciones se profundiza en las ideas anteriores y aparece como novedad la noción de territorio aunque no la de paisaje. la Carta nos acerca de modo sintético, en su introducción y en la caracterización de esta producción, a un modo cultural, natural y tradicional en que las comunidades han producido su propio hábitat, como parte de un proceso continuo, que incluye cambios necesarios y una continua adaptación como respuesta a los requerimientos sociales y ambientales.

Por último debemos hacer referencia a la Declaración de Xi'an sobre la conservación del entorno de las estructuras, sitios y áreas patrimoniales, adoptada en Xi'an el 21 de octubre 2005 con ocasión de celebrarse la XV Asamblea General de ICOMOS ${ }^{6}$. En este documento el gran protagonista es el territorio a diferentes escalas, la topografía, los valores del medio natural y los usos del suelo en donde se insertan los elementos patrimoniales. También se detecta por primera vez la consideración del paisaje como forma de entender los múltiples factores, físicos y humanos, que intervienen en la aparición y continuidad del patrimonio vernáculo. Por otro lado se continúa insistiendo en la necesidad de comprender, documentar e interpretar los entornos en contextos diversos, desarrollando instrumentos de planificación y prácticas para conservar y gestionarlo. Como medidas para su conservación se anima al seguimiento y la gestión de los cambios que amenazan el entorno y de forma encarecida se exhorta a trabajar con las comunidades locales, interdisciplinarias e internacionales para la cooperación y el fomento de la conciencia social sobre la conservación y la gestión del mismo.

Además, en el seno de la ONU se ha venido manifestando una cierta preocupación sobre los asentamientos humanos, que según esta institución se debaten entre el crecimiento y el desarrollo, los problemas ambientales, los derechos humanos y la erradicación de la pobreza. Las respuestas a estas cuestiones se expresaron en la Segunda Conferencia de las

5 Este texto publicado en 1964 incluye en la noción de monumento histórico la creación arquitectónica aislada así como el conjunto urbano o rural, a diferencia de otros textos como la Carta de Atenas de 1931 tan valorada como punto de partida del trato que debieran recibir los restos arqueológicos y grandes monumentos del pasado, pero que no tuvo igual consideración con la arquitectura tradicional.

6 Otros textos igualmente interesantes que contienen valiosa información de cara a un mejor entendimiento del hábitat tradicional y que han influido en la presente Declaración de Xi'an son las referencias al concepto de entorno en las convenciones y recomendaciones de la UNESCO como la Recomendación Relativa a la Salvaguarda de la Belleza y el Carácter de los Paisajes y los Sitios (1962), la Recomendación Relativa a la Conservación de los Bienes Culturales amenazados por Obras Públicas o Privadas (1968), la Recomendación relativa a la Salvaguarda y al Papel Contemporáneo de las Áreas Históricas (1976), la Convención para la Salvaguarda del Patrimonio Cultural Intangible (2003), y, especialmente, la Convención del Patrimonio Cultural (1972) y sus Directrices, en las que el entorno se estima como un atributo de la autenticidad que requiere protección mediante la delimitación de zonas de respeto, así como la creciente oportunidad que ello proporciona para la cooperación internacional e interdisciplinaria entre ICOMOS, UNESCO, y otras entidades, y para el desarrollo de temas como la autenticidad o la conservación de paisajes urbanos históricos, según se refleja en el Memorándum de Viena (2005). 
Naciones Unidas sobre los Asentamientos Humanos (Hábitat II) celebrada en Estambul del 3 al 14 de junio de 1996, teniendo ya como precedente la primera Conferencia de las Naciones Unidas sobre los Asentamientos Humanos, celebrada en Vancouver en 1976.

La Conferencia Hábitat II, también llamada Cumbre de las Ciudades, tenía como objetivo debatir ideas encaminadas a elaborar un Plan de acción que reflejase el compromiso de los países para mejorar el entorno y el modo de vida de los habitantes de un planeta crecientemente urbanizado. En este sentido, planteaba la necesidad de recuperar la atención sobre la ciudad, analizar los cambios económicos y sociales, revisar el enfoque de sus problemas y oportunidades, y renovar el planteamiento de las formas y usos de las ciudades, de su gestión y de sus actuaciones necesarias. En este contexto y a fin de aportar ideas y experiencias para apoyar los informes nacionales y los planes de acción se propuso a los Comités Nacionales de los diversos países reunir ejemplos de buenas prácticas que respondieran a los objetivos de la Conferencia: asentamientos humanos más sostenibles y vivienda adecuada para todos. De esta forma, durante los preparativos de la Conferencia de Naciones Unidas Hábitat II, surgió la primera Convocatoria de Buenas Prácticas como un instrumento para identificar políticas y actuaciones urbanas que, desde unos criterios de sostenibilidad, se hubiesen mostrado eficaces para mejorar las condiciones de vida en las ciudades y pueblos, y pudiesen servir como ejemplo de las nuevas tendencias y formas de actuación que se querían impulsar.

En nuestro país se ha concretado una Agenda Hábitat España: contribución de las ciudades al desarrollo sostenible, documento editado por el Ministerio de Fomento con ocasión de la conferencia Hábitat II, que se centra en los problemas propios que presenta un tipo de ciudad y que es la de los países desarrollados: problemas relacionados con la aparición de nuevos conflictos entre la ciudad y su territorio, con la movilidad de los ciudadanos, la sostenibilidad medioambiental, los problemas de vivienda, la gobernabilidad de las ciudades, cuestiones de habitabilidad urbana y calidad de vida, etc.

También se ha publicado un Catálogo español de Buenas Prácticas que en sucesivas ediciones tiene como finalidad difundir los proyectos relacionados con las buenas prácticas que se desarrollan en nuestro país y que participan en el Concurso Internacional de Buenas Prácticas. Los trabajos presentados en su mayoría se refieren al ámbito urbano pero cada vez son más los que prestan atención a los pequeños municipios y pueblos de Andalucía, si bien todavía no hemos encontrado ninguno referido a nuestro ámbito de estudio. Lo cierto es que tanto el programa como el concurso constituyen un lugar privilegiado, aunque poco explotado, para promover iniciativas relacionadas con la protección y la difusión de la arquitectura rural mariánica.

Desde luego no faltan referentes internacionales que sirvan de modelo y guía para los oportunos proyectos, intervenciones o difusión de nuestro patrimonio rural como tampoco faltan figuras y modelos de protección en donde inscribir nuestro patrimonio vernáculo a una escala regional. Nos gustaría resaltar, a continuación, algunas de estas posibilidades.

Dentro de los mecanismos existentes para su efectiva protección, el inventario es una herramienta de gran utilidad pues sólo el reconocimiento de su existencia garantiza su protección. Se debe emplear con la finalidad de recoger y dejar constancia de los testimonios arquitectónicos de los diferentes municipios que conforman la comarca. A su vez, ha de ser lo suficientemente amplio para reflejar las distintas tipologías existentes, indagando desde las infraviviendas hasta las viviendas de grandes propietarios, así como los edificios relacionados con las actividades productivas: almazaras, molinos, etc. 
Han sido claves las obras e inventarios ${ }^{7}$ publicados por la Consejería de Obras Públicas y Transportes, y la Consejería de Cultura, las cuales desde sus respectivos ámbitos administrativos y propios enfoques, han aportado no solo su visión de este patrimonio sino que han puesto de manifiesto la profusión, riqueza y variedad del mismo en todas las provincias andaluzas, así como su fragilidad y necesidad de protección.

Desde una perspectiva autonómica debemos destacar la extensa publicación de la Consejería de Obras Públicas y Transportes (1998) que cataloga las principales edificaciones rurales de Andalucía por provincias. En ella se recogen por comarcas agrarias las principales construcciones rurales, diferenciando el tipo de explotación que sostienen, una descripción de sus dependencias, planimetría, imágenes y notas de carácter histórico que hacen referencia a la misma.

El Catálogo General del Patrimonio Histórico Andaluz (C.G.P.H.A) ${ }^{8}$ constituye otra iniciativa autonómica básica para facilitar la tutela jurídico-administrativa del Patrimonio Histórico entre el que se encuentra la vivienda rural. Además, el catálogo incluye las inscripciones como Bienes de Interés Cultural al amparo de la Ley 16/1985 de 25 de junio del Patrimonio Histórico Español entre otras figuras de protección. El Instituto Andaluz del Patrimonio Histórico (IAPH) ${ }^{9}$ ha asumido el concepto de paisaje cultural ${ }^{10}$ adoptado por la UNESCO. Según las directrices operativas para la aplicación de la Convención del Patrimonio Mundial, los paisajes culturales se consideran bienes culturales que ilustran la evolución de la sociedad humana a lo largo del tiempo, bajo la influencia de limitaciones físicas y/o de posibilidades presentadas por su medio ambiente natural y de fuerzas sociales, económicas y culturales sucesivas, tanto externas como internas. Acogiéndose a esta figura, en nuestra zona de estudio, destaca La Encomienda de León (Arroyomolinos de León y Cañaveral de León, Huelva) dentro de la Demarcación Paisajística $n^{o} 24$ de Sierra Morena. Este paisaje de interés cultural tiene como elemento definidor el agua y su canalización para el aprovechamiento molinero y de riego de las huertas. Se expresa en las construcciones que jalonan su paisaje. Pero, desentona a nuestro entender, el amplio de abanico de figuras y tipologías de patrimonio que se contemplan, entre las que se incluye la vivienda rural y otras dependencias de transformación rurales, con el reducidísimo número de edificios considerados por el Instituto Andaluz de Patrimonio Histórico y que no alcanza a cubrir siquiera un ejemplar para cada uno de los modelos de explotación agropecuaria existentes en Sierra Morena.

7 Nos referimos, por ejemplo, a la inclusión de las edificaciones rurales en la Base de datos de Patrimonio Inmueble de Andalucía (BDI) que forma parte del Sistema de Información del Patrimonio Histórico de Andalucía (SIPHA). La BDI contiene 3.822 registros de diferentes tipologías funcionales cuya fuente de información principal es el Inventario de Arquitectura Popular. Destaquemos, también la extensa y pormenorizada publicación con tomos provinciales de la obra de la Junta de Andalucía: Cortijos, haciendas y lagares. Sevilla, Conserjería de Obras Públicas y Transportes, 1999.

8 El Estatuto de Autonomía para Andalucía establece en el artículo 12.3 uno de los objetivos básicos de la Comunidad Autónoma: «afianzar la conciencia de identidad andaluza, a través de la investigación, difusión y conocimiento de los valores históricos, culturales y lingüísticos del pueblo andaluz en toda su riqueza y variedad», atribuyendo el artículo 13.27 de la misma norma legal la competencia exclusiva de la Comunidad Autónoma en materia de Patrimonio Histórico, Artístico, Monumental, Arqueológico y Científico. El Catálogo General del Patrimonio Histórico Andaluz se crea por Ley 1/1991, de 3 de julio, de Patrimonio Histórico de Andalucía «como instrumento para la salvaguarda de los bienes en él inscritos, la consulta y la divulgación del mismo».

9 Es desde el 26 de junio de 2007, una agencia pública dependiente de la Consejería de Cultura de la Junta de Andalucía.

10 Según lo fijado en el Convenio Europeo del Paisaje del Consejo de Europa en su Artículo 1, se entiende por paisaje cualquier parte del territorio, tal como lo percibe la población, cuyo carácter sea el resultado de la acción e interacción de factores naturales y/o humanos. 
Lo dicho hasta el momento hace referencia a la arquitectura tradicional dispersa en el medio rural pero las viviendas urbanas tradicionales, que en su mayoría no son ni edificios históricos, ni monumentos, ni iglesias, también necesitan de un adecuado planeamiento urbanístico, mediante medidas de diversa índole, ya que forman naturalmente, la esencia de los núcleos rurales.

Muchos conjuntos urbanos y su caserío han encontrado en la categoría de Conjunto Histórico la figura de protección adecuada para preservar no solo las construcciones más sobresalientes sino el entorno que las rodea. La categoría de Conjunto Histórico se define en la Ley de Patrimonio Histórico Español ${ }^{11}$, en su artículo 15.3 como «la agrupación de bienes inmuebles que forman una unidad de asentamiento, continua o dispersa, condicionada por una estructura física representativa de la evolución de una comunidad humana por ser testimonio de su cultura o constituir un valor de uso y disfrute para la colectividad». En definitiva se trata de agrupaciones homogéneas de construcciones urbanas o rurales que sobresalen por su interés histórico, arqueológico, artístico, científico, social o técnico, con coherencia suficiente para constituir unidades susceptibles de clara delimitación.

En el ámbito de nuestra Comunidad Autónoma nos podemos encontrar con conjuntos de interés cultural los cuales pueden, a su vez, estar o no catalogados y con conjuntos simplemente catalogados. Los primeros sujetos al especial régimen uniforme de protección establecido en la Ley estatal de 1985 completado, en su caso, con lo dispuesto en la norma autonómica; los segundos al régimen específico que para cada uno de ellos se establezca en las Instrucciones que acompañen a la inscripción.

Los municipios cumplen un papel fundamental, ya que son requisito indispensable en el planeamiento de desarrollo. Así los Planes Especiales de Protección - PEP - o los Planes Especiales de Protección y Reforma Interior - PEPRI - ligados a la figuras de protección de Conjunto Histórico o el Lugar de Interés Etnológico, requieren de una adecuación del planeamiento urbanístico tanto de la normativa estatal como la autonómica a dicha circunstancia.

Un plan como el que se refiere conlleva toda una serie de medidas como: establecer el orden de instalación para los usos públicos en los edificios y espacios adecuados para ello, rehabilitar áreas que permitan la recuperación del uso residencial y de las actividades económicas adecuadas, incluir los criterios relativos a la conservación de fachadas y cubiertas e instalaciones sobre las mismas, etc.; pero además, requiere la utilización de instrumentos de planeamiento referidos tanto a inmuebles edificados como espacios libres exteriores o interiores, u otras estructuras significativas, así como de los componentes naturales que lo acompañan, definiendo los tipos de intervención posible, dispensándoles una protección integral a los elementos singulares, así como un adecuado nivel de protección.

En nuestro ámbito de estudio se localizan los Conjuntos Históricos catalogados como B.I.C. del Centro Histórico de Alájar, de Almonaster la Real, de Aracena, de Aroche, de Castaño del Robledo, de Corteconcepción, de Cortelazor, de Fuenteheridos, de Galaroza, de Higuera de la Sierra, de Linares de la Sierra, de Los Marines, de Valdelarco y de Zufre en Huelva; los Conjuntos Históricos de Cazalla de la Sierra y de Constantina en Sevilla; los Conjuntos Históricos de Montoro y Dos Torres en Córdoba; y el de Baños de la Encina en Jaén. Muchos de ellos se integran a su vez en La Red de Conjuntos Históricos y de Arquitectura Popular de Andalucía (Red Patrimonia) que es promotora de la Iniciativa de Ciudades Turísticas «Conjuntos Históricos de Andalucía. Red Patrimonia» acogida a la Estrategia de Turismo Sostenible de la Consejería de Turismo, Comercio y Deporte de la Junta de Andalucía.

\footnotetext{
11 LEY 16/1985, de 25 de junio.
} 
Ahora bien, la ordenación urbanística en los municipios que no cuentan con ningún Plan Especial de Protección ha tenido como herramienta habitual los Planes generales de Ordenación Urbana (PGOU) y las Normas Subsidiarias (NNSS). No obstante la Ley de Ordenación Urbanística de Andalucía ${ }^{12}$, ha introducido toda una serie de cambios lo que no es inconveniente para que la mayoría de los ordenamientos existentes en la actualidad deriven directamente de las NNSS municipales anteriores, pues salvo los municipios que han elaborado un PGOU en el resto de casos se han llevado a cabo meras adaptaciones a la referida normativa sin cambios significativos. Dichas normas incluyen varios aspectos, pero desde luego el más interesante por lo que respecta a la arquitectura tradicional, es el relacionado con las normas de edificación dentro de los cascos históricos, y que se relacionan con el mantenimiento del aspecto tradicional de los caseríos aunque con aplicaciones desiguales y resultados bastante regulares

Otro elemento de gran importancia dentro del planeamiento, y parte integrante de las NNSS, es el Catálogo para la protección del patrimonio en sus múltiples acepciones. No siempre está presente en todas ellas y, a la sumo, solo recoge los edificios considerados como más importantes o sobresalientes de la localidad como castillos y parroquias, aunque también algunas casas nobiliarias y edificios públicos civiles como puedan ser los ayuntamientos. Por ello, es normal que los inmuebles de interés relacionados con la actividad agraria, como molinos, aceñas, lagares, cortijos, etc., situados casi siempre en suelo no urbanizable, no aparezcan en los mismos. Por lo que respecta a las viviendas tradicionales del casco urbano, tampoco salen muy bien paradas, pues su nivel de protección es muy comedido.

La Consejería de Medio Ambiente se suma también a la apreciación de la vivienda rural que se ubica dentro de los ENP, particularmente dentro de los Parques Naturales y posibilita la intervención en ella mediante su inclusión en los Planes de Ordenación de los Recursos Naturales (PORN) y los pertinentes Planes Rectores de Uso y Gestión (PRUG). En Sierra Morena existen amplios Parques Naturales que abarcan una importante superficie y comprenden numerosos municipios. En sus respectivos documentos se diferencia en primer lugar la categoría de vivienda rural de las viviendas aisladas de nueva planta no vinculadas a actividades productivas y que quedan totalmente prohibidas. En cuanto a las viviendas rurales aisladas vinculadas a la explotación de los recursos naturales se insiste en la necesidad de adecuar el saneamiento y se requieren permisos para su ampliación o cambio de uso para otras actividades como puedan ser las relacionadas con el turismo rural. Estas directrices supone desde luego una interesante revalorización de la vivienda rural en los ENP y un incentivo para su mantenimiento, fomentando unos usos que pueden ser claves para su recuperación al poder acogerse a cuantas medidas se instrumenten con miras al desarrollo de la zona.

Un análisis crítico de las normas edificatorias y catálogos, así como del planeamiento de desarrollo, nos lleva a extraer una serie de conclusiones acerca de la capacidad del planeamiento urbanístico actual por lo que respecta a la arquitectura tradicional, son estas:

- El planeamiento existente presenta notables deficiencias: primero en el conocimiento de los bienes que contempla o debiera contemplar, pues de lo contrario no seguirían desapareciendo ejemplares irreemplazables; segundo, en lo concerniente a las normas edificatorias relacionadas con las alturas, las cubiertas, fachadas, etc. resultando inaceptable la permisibilidad de muchos ayuntamientos en estas cuestiones de lo que se deriva la destrucción del caserío tradicional y el deterioro de la calidad paisajística de los municipios.

12 Ley $7 / 2002$ de 17 de Diciembre. 
- Por lo que respecta al Catálogo, el principal problema se encuentra en el deficiente nivel de protección que encuentra la arquitectura tradicional dentro del mismo. Ocupa la última categoría y es tratada habitualmente como telón de fondo de otros edificios supuestamente más representativos para la comunidad, como son las iglesias y castillos.

- Los ayuntamientos cuentan con una serie de herramientas útiles como las licencias municipales que son un trámite reglado y obligatorio que permite que sea el poder local el que con el otorgamiento o no de un permiso de obra se pueda actuar a favor de la protección y conservación del patrimonio. Así las corporaciones locales gozan por tanto de un margen para impedir las acciones negativas. Además, para la realización de acciones en bienes catalogados, se pueden pedir informes, no teniendo que emitir licencia el ayuntamiento mientras todos no sean positivos. De esta manera, se puede afirmar que los municipios tienen mecanismos adecuados para la salvaguarda de la arquitectura tradicional mediante la denegación, modificación o paralización de las obras cuando se incumplan los términos. No son tolerables por tanto los atentados contra la vivienda rural y la calidad paisajística de los municipios, debiendo exigirse responsabilidades en el caso de producirse.

- Pero el cumplimiento efectivo de la normativa urbanística no es la panacea, es preciso articular un conjunto de medidas que procuren unificar las actuaciones a efectuar desde un punto de vista científico, sin perder de vista que cada municipio tiene unas características urbanas propias y unas tipologías especificas. Como quiera que los núcleos rurales mariánicos no han evolucionado de la misma forma, existiendo un centro histórico tradicional y unos crecimientos posteriores modernos en donde se ubica la arquitectura rural de forma desigual; es por lo que se debieran de establecer criterios de zonificación o ámbitos espaciales diferenciados con una normativa adecuada a cada uno de ellos. Así en los centros históricos se aplicaría una normativa más restrictiva y protectora de la arquitectura tradicional, mientras que en la zona de más reciente aparición se procuraría que no se produjesen discordancias con el paisaje urbano; intentando compatibilizar las nuevas construcciones con las antiguas siendo posible la construcción de edificios que evoquen o incluso realcen visualmente los existentes.

- Conviene insistir en que la vivienda rural tradicional no es un hecho aislado por lo que es necesario trabajar siempre con la perspectiva de los paisajes urbanos y rurales de manera que se mantenga la integración espacial y funcional entre ambos. Este el sentido de procurar guardar la estética en las normas edificatorias debiendo de dar el paso de una mera recomendación a la obligatoriedad de un estricto cumplimiento de las mismas.

\subsection{La consideración institucional del paisaje}

La consideración institucional del paisaje no ha corrido un tratamiento normativo similar al del patrimonio. En primer lugar su andadura ha sido mucho más tardía puesto que el propio concepto ha madurado recientemente, incluyéndose de forma bastante tímida en los inventarios, informes y normativas como aglutinador de valores estéticos, exponente cultural e histórico del territorio, e incluso, como aglutinador de identidades colectivas. En segundo lugar no se detecta, en bastantes ocasiones, la mínima valoración por parte de la opinión pública en lo que se refriere a los paisajes agrarios y a la vivienda rural como parte integrante de aquellos, por lo que podemos decir con Mata Olmo (2004) que, si bien, el patrimonio es algo ya reconocido por las instituciones y cuenta con cierto predi- 
camento social, no ocurre lo mismo con el término de paisaje, que continua anclado en las bellezas panorámicas y estéticas a modo de escenario turístico en los planes de desarrollo, prescindiendo del paisanaje y olvidando la identificación con el territorio y la salvaguarda generalizada de los valores patrimoniales del paisaje.

El Estado español ha ratificado recientemente, en 2004, el Convenio Europeo del Paisaje, si bien no ha desarrollado todavía una legislación sobre el tema, lo que no es óbice para que algunas Comunidades Autónomas en uso de sus competencias se hayan lanzado a ello, tras una considerable aceptación de las premisas del CEP. Destaquemos la ley de la Generalitat Valenciana ${ }^{13}$, la de Cataluña ${ }^{14}$ o la de Galicia ${ }^{15}$ o los documentos: el Catálogo de Paisajes singulares y sobresalientes (2005) del País Vasco, el Atlas de los Paisajes de Murcia (2009), el documento Estrategia del Paisaje (2009) del Consell Insular de Menorca, el Estudio y Cartografía del Paisaje de La Rioja (2009) o la elaboración del Atlas de Paisaje de Aragón (en realización), estudios que toman como referencia singular el Atlas de los Paisajes de España (2003) del Ministerio de Medio Ambiente.

En Andalucía podemos destacar los trabajos que viene realizando el Centro de Estudios Paisaje y Territorio (CEP) creado en 2005 mediante un convenio marco de colaboración suscrito entre la Consejería de Obras Públicas y Transportes de la Junta de Andalucía y las universidades andaluzas con el objetivo de fomentar la interacción entre las respectivas líneas de actividad, investigadoras, científica y docentes en el ejercicio de competencias en materia de paisaje y ordenación del territorio.

De todas estas iniciativas podemos decir que se derivan importantes implicaciones para la consideración y gestión de los paisajes agrarios y de la vivienda rural tanto en diseminado como en los núcleos de población. Consideraciones que primero identifican, a continuación caracterizan - aunque mínimamente - y, finalmente, ponen en valor las construcciones tradicionales mediante catálogos de buenas prácticas o cartas del paisaje en las que se recomienda la armonización de las nuevas edificaciones con las construcciones tradicionales y con los edificios de valor etnográfico o arquitectónico que existan en el entorno inmediato rechazando las construcciones que presenten características tipológicas o soluciones estéticas propias de las zonas urbanas.

\section{Conclusiones}

Constatamos por tanto dos conceptos — patrimonio y paisaje - íntimamente relacionados, pero que han caminado por separado hasta el momento. El primero, que dejaba fuera de toda consideración los espacios de la agricultura en una atención restringida de la cultura, ha emprendido un reconocimiento temático y territorial de las prácticas agropecuarias como parte integrante del patrimonio natural. El segundo, por su parte, que consideraba a la agricultura como proveedora de recursos para la sociedad, ahora la dota de una nueva aportación relacionada con la provisión de recursos postproductivos a dicha sociedad, como es el suministro de paisajes agrarios singulares (Silva, 2009). Así, como consecuencia de la convergencia del patrimonio y del paisaje sobre los paisajes de la agricultura y sobre uno de sus elementos más señeros - el hábitat-, estos - por primera vez en la historia - comienzan a adquirir una nueva dimensión jurídica conducente a su consideración como patrimonio.

Esta nueva consideración llega por tanto en el momento más oportuno, cuando la crisis originada por la especialización e intensificación de la agricultura actual ha provocado la

13 Ley 4/2004, de 30 de junio, de la Generalitat Valenciana, de Ordenación del Territorio y Protección del Paisaje.

14 Ley 8/2005 de Protección, Ordenación y Gestión del Paisaje de Cataluña

15 Ley $7 / 2008$, de 7 de julio, de protección del paisaje de Galicia. 
banalización de sus paisajes (López Ontiveros, 1993), la despoblación, la pérdida del hábitat, e incluso el abandono de la actividades agrarias y otros elementos paisajísticos que los campesinos y las diferentes culturas fueron acrisolando a lo largo del tiempo. Aunque estos dos factores se hayan conjugado para que las viviendas rurales muestren una inercia poco favorable a los cambios y transformaciones que presentan otros hechos geográficos, lo cierto es que en el presente, el hábitat rural a reaccionado en los espacios mariánicos, de igual forma que en toda Andalucía, ante las innovaciones derivadas del uso de nuevas técnicas y materiales y ante los cambios en los modos de vida. Esas modificaciones han acarreado la estandarización de las tipologías y de los materiales, de manera que cada paisaje ha ido perdiendo aquellos componentes que caracterizaban sus propias formas de hábitat.

Por otro lado, se ha producido una disociación entre las funciones que se han atribuido a la casa rural, funciones de alberge, almacén, taller, corral y huerto. Ahora estas funciones se realizan en lugares y en edificios diferentes. La casa rural es ahora un organismo sin función directamente vinculada al hecho agrícola aunque sus moradores sigan teniendo como ocupación las tareas del campo. Finalmente, el abandono de las viviendas diseminadas como lugares de residencia permanente, favorecido por el avance de los transportes y las comunicaciones, ha incidido en una mayor diferenciación entre la vivienda urbana campesina y la agrícola. La primera ha evolucionado hacia un alojamiento estandarizado y la segunda hacia un simple lugar de almacén para los aperos o como taller agrícola.

Nadie pone en duda que la arquitectura rural tradicional posee un alto valor patrimonial y paisajístico. De igual forma, todos coinciden a la hora de afirmar que este patrimonio tan extenso, por su riqueza y variedad, debe contemplarse desde una perspectiva conservacionista, preservando los ejemplares más señeros o mejor conservados de cada tipo. Pero, para los geógrafos, la destrucción de estos edificios o, por el contrario, la conservación solo de algunos ejemplares significativos nunca podrá compensar la pérdida de un conjunto necesario para poder explicar los paisajes rurales que siguen ante nosotros (Zoido, 1979). No debernos olvidar que el hábitat rural de las tierras andaluzas y particularmente de los espacios mariánicos constituye una de las expresiones más acabadas de nuestra historia y cultura, y que encierra un cúmulo de valores geográficos, históricos, artísticos, arquitectónicos antropológicos y paisajísticos de los cuales debe tomar plena conciencia nuestra sociedad, de forma que mediante planes de protección, recuperación y aprovechamiento se asegure su pervivencia para las generaciones futuras.

Uno de los mayores peligros radica, justamente en su desconocimiento, en la ignorancia acerca de su singularidad, de su pasado y de los valores que encierra. Su preservación pasa por un definitivo cambio de actitudes ante la misma: tanto por parte de las administraciones que debieran de articular medidas coherentes dirigidas a su puesta en valor y conservación; como por el, no menos importante, cambio de actitudes y valoraciones peyorativas, que persisten en muchos casos, por quienes siguen habitándolas o son sus vecinos (Agudo, 1999).

Para conseguir este objetivo la arquitectura tradicional o vernácula debe ser interpretada, antes que nada, como testimonio privilegiado que nos habla de la riqueza y diversidad de los paisajes agrarios de las comarcas mariánicas, vinculados a su faceta productiva y lejos del riesgo de tematización que comporta el abandono de los usos y saberes tradicionales

En definitiva, podemos decir que la vivienda rural mariánica, parte esencial de los paisajes rurales mariánicos, cuenta con personalidad propia, se ha forjado lentamente, en una dilatada evolución histórica, a partir de los componentes naturales del paisaje y con el concurso de los hechos humanos, resultando un patrimonio identitario, rico, complejo y variado, de gran permanencia en los paisajes rurales mariánicos y que actualmente vienen padeciendo una profunda y grave crisis, no solo de identidad, sino de supervivencia. Crisis 
que en buena parte podría paliar la nueva consideración que se hace del patrimonio y del paisaje.

\section{Bibliografía}

AGUDO TORRICO, J. (1984): «Arquitectura popular en la provincia de Sevilla», en Sevilla y su provincia. Ed. Gever, S.A., pp. 117-147.

AGUDO TORRICO, J. (1999): «Arquitectura tradicional. Reflexiones sobre una arquitectura en peligro», en PH: Boletín del Instituto Andaluz del Patrimonio Histórico, $\mathrm{n}^{\circ}$. 29, Sevilla, pp. 191-192.

AGUILAR GARCIA, M.C. (1992): Las haciendas: arquitectura culta en el olivar de Sevilla. Sevilla, Secretariado de Publicaciones de la Universidad de Sevilla.

ARAMBURU MAQUA, M.P., ESCRIBANO BOMBÍN, R., LÓPEZ HERNÁNDEZ, R., SÁNCHEZ RAMOS, P. (2004): Estudio y Cartografía del Paisaje de la Comunidad Autónoma de La Rioja. Consejería de Turismo, Medio Ambiente y Política Territorial, Gobierno de La Rioja.

BERGES ROLDAN, L. (1986): Arquitectura rural de la Sierra de las 4 Villas. Jaén, Diputación Provincial.

CARO BAROJA, J. (1990): Arquitectura popular en España. Madrid, C.S.I.C.

Convención Europea del Paisaje. París, 1997.

CONSEJERÍA DE OBRAS PÜBLICAS Y TRANSPORTES. JUNTA DE ANDALUCÍA, (1990): Inventario de toponimia andaluza. Sevilla, Centro de Estudios Territoriales y Urbanos.

DÍEZ CALPENA, V. (2009): Atlas de los paisajes de la región de Murcia Consejería de Obras Públicas y Ordenación del Territorio. Comunidad Autónoma de Murcia.

CRUZ VILLALÓN, J. (1980): Propiedad y uso de la tierra en la Baja Andalucía. Carmona, S. XVIII-XX. Madrid, Ministerio de Agricultura Pesca y Alimentación.

DEFFONTAINES, I. (1972): L`homme et sa maison. París, Ed. Gallimard.

DEMANGEON, A. (1963): Problemas de Geografía Humana. Barcelona, Ed. Omega, pp. 157-158.

DERRUAU, M. (1981): «Los problemas del hábitat rural», en Tratado de Geografía Humana. Barcelona, Vicens-Vives, pp. 239-266.

DIRECCION GENERAL DE ARQUITECTURA Y VIVIENDA, (1998): Cortijos, Haciendas y Lagares. Arquitectura de las grandes explotaciones agrarias de Andalucía. Avance del estudio inventario, Sevilla, Consejería de Obras Públicas y Transportes de la Junta de Andalucía.

FEDUCHI, L. (1978): «Los pueblos blancos» en Tomo IV de Itinerarios de arquitectura popular española. Barcelona, Ed. Blume.

FLORES, C. (1973): Arquitectura popular española. Madrid, Ed. Aguilar, S.A.

FLORIDO TRUJILLO, G. (1996): Hábitat rural y gran explotación en la Depresión del Guadalquivir. Consejería de Obras Públicas y Transportes de la Junta de Andalucía, Sevilla.

FLORIDO TRUJILLO, G. (2003): «Poblamiento y hábitat rural: caracterización, evolución y situación actual» en Geografía de Andalucía. Barcelona, Ariel, pp. 328-357.

GALIANA MARTÍN, L.; MATA OLMO, R. (1996): «La política agroambiental en Francia y el tratamiento de las zonas de montaña», en VIII Coloquio de Geografía Rural. Actas: Comunicaciones. Zaragoza: Universidad de Zaragoza; A.G.E. pp. 121-131.

GARCÍA GRINDA, J.L. (2007): «La arquitectura tradicional mediterránea. Territorio, paisaje y arquitectura tradicional», en Método RehabiMed. Arquitectura Tradicional 
Mediterránea. Barcelona, Collegi d'Aparelladors i arquitectes Tècnics de Barcelona para el consorcio RehabiMed, pp. 49-66.

GARCÍA MERCADAL, F. (1981): La casa popular en España. Barcelona, Ed. Gustavo Gili, S.A.

GOUROU, P. (1979): Iniciación a la Geografía Humana. Madrid, Alianza.

JUNTA DE ANDALUCÍA (1999): Plan de Ordenación del Territorio de Andalucía. Sevilla, Consejería de Obras Públicas y Transportes.

LÓPEZ ONTIVEROS, A. (1973): Emigración, propiedad y paisaje agrario en la Campiña de Córdoba. Barcelona, Ed. Ariel.

LÓPEZ ONTIVEROS, A. (1988): «El paisaje de Andalucía a través de los viajeros románticos: creación y pervivencia del mito andaluz desde una perspectiva geográfica», en Viajeros y paisajes. Madrid, Alianza Universidad, pp. 31-65.

LÓPEZ ONTIVEROS, A., VALLE BUENESTADO, B. (direc.) (1989): Caza y explotación cinegética en las provincias de Córdoba y Jaén. Instituto Andaluz de Reforma Agraria. Córdoba.

LÓPEZ ONTIVEROS, A. (1999): «El reto de la protección y gestión de los países rurales andaluces», en Cuadernos Geográficos, n. ${ }^{\circ}$ 29, pp. 69-83.

MARTÍNEZ DE PISÓN, E. (1977): «La evolución antrópica y la transformación voluntaria de los paisajes naturales», en V Coloquio de Geografía. Granada, Universidad de Granada, pp. 157-161.

MATA OLMO, R. (1987): Pequeña y gran propiedad agraria en la Depresión del Guadalquivir. Madrid, Ministerio de Agricultura, Pesca y Alimentación.

MATA OLMO, R. (2004): «Agricultura, paisaje y gestión del territorio», en Revista de Geografía, n $^{\circ}$ 14, pp. 97-137.

MATA OLMO, R. y SANZ HERRÁIZ C. (2004): Atlas de los paisajes de España. Ministerio de Medio Ambiente, Centro de Publicaciones.

RAMIREZ LAGUNA, A. (1985): «Arquitectura popular. La vivienda tradicional en la provincia de Córdoba», en Córdoba y su provincia. T. IV. Obra Cultural de la Caja Provincial de Ahorros de Córdoba, Géver, pp. 290-319.

SILVA PÉREZ, R. (2009): «Agricultura, paisaje y patrimonio territorial. Los paisajes de la agricultura vistos como patrimonio». Boletín de la A.G.E. n. ${ }^{\circ} 49$, pp. 309-334.

SORRE, M. (1952): Les Fondemens de la Géografie Humaine. Vol. III (L'habitat). Paris, Ed. A. Colin.

SUÁREZ JAPÓN, J. M. (1982): El hábitat rural en la Sierra de Cádiz. Un ensayo de Geografía de poblamiento. San Fernando, Excma. Diputación de Cádiz.

VALLE BUENESTADO, B. (1978): «Los huertos familiares de la provincia de Córdoba», en Cuadernos Geográficos de la Universidad de Granada, n. ${ }^{\circ}$ 8, pp. 259-269.

ZOIDO NARANJO, F. (1979): «Conocer el hábitat rural: una urgente necesidad científica», en Estudios Geográficos, n. ${ }^{\circ}$ 154, pp. 228-234.

ZOIDO NARANJO, F. (2000): «El paisaje, ideas para la actuación», en Estudios sobre el paisaje. Madrid, Fundación Duques de Soria-UAM, 293-304.

ZOIDO NARANJO, F. (2002): «El paisaje y su utilidad para la ordenación del territorio», en Paisaje y ordenación del territorio. Sevilla, Junta de Andalucía-Fundación Duques de Soria, 21-32.

ZOIDO NARANJO, F. (2004): «El paisaje, patrimonio público y recurso para la mejora de la democracia», en PH: Boletín del Instituto Andaluz de Patrimonio Histórico $\mathrm{n}^{\circ}$ 50, 66-73. 